\title{
THE SEASON FOR PLUMS ... AND FOR LASER AND LIGHT-BASED DEVICE MEETINGS
}

\author{
Toshio Ohshiro MD PhD
}

A warm (but wet) welcome, literally, from Tokyo, where we are "enjoying" our annual "tsuyu" or rainy season. The term actually means "plum rain" because it is associated with the seasonal ripening of the green plum known here as "ume". While still green, they can be layered in a suitable container with rock sugar crystals and covered in clear liquor with an alcohol content of around $37 \%$, then left for a minimum of 6 months, although in general the longer it is left, the tastier is the resulting liquor. This is called "Umeshu", or plum wine, and is enjoyed straight, on the rocks, or as a long drink with ice and soda which makes it a really refreshing summertime drink. When the plums start to turn orange-yellow, they are ready to be dried and pickled to produce the mouth-puckering but refreshing "umeboshi", pickled plums. However, more importantly for Laser Therapy, this is also the season for a number of important meetings of societies for laser- and light-based medicine, who are also using Laser Therapy as their official organ. By the time you read this, the European Association for Laser Aesthetic Surgery (ESLAS) will have held their annual meeting under the banner of the European Laser Association and in cooperation with the Dutch Laser Association, in beautiful Athens (June $25^{\text {th }}-27^{\text {th }}$ ). I hope as many of as possible will have supported this meeting which had a very strong LLLT component.

Then at the beginning of July, on the $9^{\text {th }}$ and $10^{\text {th }}$, there will be the $6^{\text {th }}$ meeting of the International Phototherapy Association (IPTA), in Nice on the French Riviera. The program of abstracts of this meeting is printed elsewhere in the journal, from which you can see there is a large variety of subjects covered by some of the acclaimed international experts in the field. Take a look at www.ipta6congress.international - it is probably too late to submit an abstract, but never too late to book for the warm and sunny venue of Nice and enjoy a strong scientific and excellent social program under the care of Professors Jean-Paul Roca, aided and abetted by Professors Carlo Fornaini and Leonardo Longo.
In August, The $21^{\text {st }}$ Congress of the International Society for Laser Medicine and Surgery (ISLSM), will take place from the $20^{\text {th }}$ to the $22^{\text {nd }}$ of the month, in the Hotel Fortune Landmark, Indore, in the very heart of central India. The ambitious programme is developing nicely under the Congress President and ISLSM President-Elect, Dr Sharon Rau, and the Chairman of the Organizing Committee, Prof Krishna Rau. Please visit www.islsm2015.com.

As part of the run-up to the ISLSM in India, I had planned to make this a "Focus on India" issue. However, because of a conflict with the number of refereed and accepted papers, other papers already in line for publication, and the necessity to publish the abstracts from the $6^{\text {th }}$ IPTA meeting, this issue was called "Focus on India, Part 1". Volume 2:3 will be Focus on India, Part 2, when we will publish some more papers from our Indian colleagues.

Although it is not a meeting with roots in the journal, another interesting meeting for Laser Therapy readers to think about putting in their calendars is the 5CC (Five Continents' Congress) meeting in Cannes, France, September $3^{\text {rd }}$ to $6^{\text {th }}$. This meeting attracts more and more attendees with a larger faculty each year, with R Glen Calderhead on faculty this year to represent the interests of the journal, the WFSLMS, ISLSM and IPTA. Dr Michael Gold is the Congress President, and details can be found by visiting http://www.5-cc.com/cannes-2015/home/. The Call for Abstracts has gone out, and abstract submission details can be found on the website in addition to the tentative programme.

\section{Honouring Mr Vasant Oswal MB MS FRCS (Ed), FRCS (Eng)}

It is always a pleasure for the journal, and a personal pleasure for me as Editor-in-Chief, to pay tribute to any honours given to members of our laser "family" in the ISLSM and WFSLMS. The honouree for this mention is Mr Vasant Oswal, Emeritus Consultant ENT Surgeon, 
James Cook University Hospital, UK; Vice President, British Medical Laser Association; and Secretary General, European Laser Association. Just in case anyone thinks I am showing disrespect to Mr Oswal by calling him "Mr", that is the correct form of address for consultant surgeons in the British medical hierarchy, to distinguish them from "mere" doctors. Already a Fellow of the Royal College of Surgeons of Edinburgh by examination since 1967, Mr Oswal has now been awarded 'Fellow of the Royal College of Surgeons of England - FRCS (Eng) - by election with a unanimous vote of the Council. This 'High Honour' of Fellowship by Election is an award by the Council of the College for those who are medically or dentally qualified in recognition of outstanding professional service to the College or national distinction in surgery. The Royal College of Surgeons of England is a highly respected professional membership organisation and registered charity, representing surgeons in the UK and abroad. The RCS often advises Government on matters medical, continuously advances surgical standards and improves care for patients: a Fellowship by Election is a really high honour. Mr Oswal was informed of this great tribute by a personal letter from Miss Claire Marx MBE DL PRCS, the current President of the RCS.

In his grateful and humble reply, Mr Oswal wrote; "It was some sixty years ago, in 1955, that I entered the medical college at the time when Penicillin was just coming in. Little did I imagine then that I will receive such a high accolade from the Worldrenowned prestigious Royal College of Surgeons of England - in the year that I qualify to be an octogenarian.”

On a personal note, my wife and I are proud to be counted as personal friends of Vasant and his charming wife Nirmal. Vasant and Nirmal have faithfully attended our ISLSM and WFSLMS meetings, in addition to the meetings held under the umbrella of the European Laser Association. Vasant served as a former Treasurer of the WFSLMS, although, as he always said; "There are no funds to manage!" Of course this is true, but it was his calming effect on the correct democratic running of Executive Meetings which was most valuable, even if his Treasurer's Report was a very easy one to give. I should like to take a moment to explain a little why the WFSLMS appears to have no funds. All the activities of the WFSLMS, as I have written before in the journal, are actually funded by NPO-WFSLMS, the non-profit wing based in Japan, and which does keep stringent financial records of all activities, incoming funds and disbursements, so the WFSLMS doesn't actually need to maintain funds in an account. However, funds for mailings and such like are provided on request by NPO-WFSLMS.

In conclusion, and to get back on track, I am sure all readers of the journal will join with me in heartily congratulating $\mathrm{Mr}$ Vasant Oswal on his Fellowship of the Royal College of Surgeons of England!

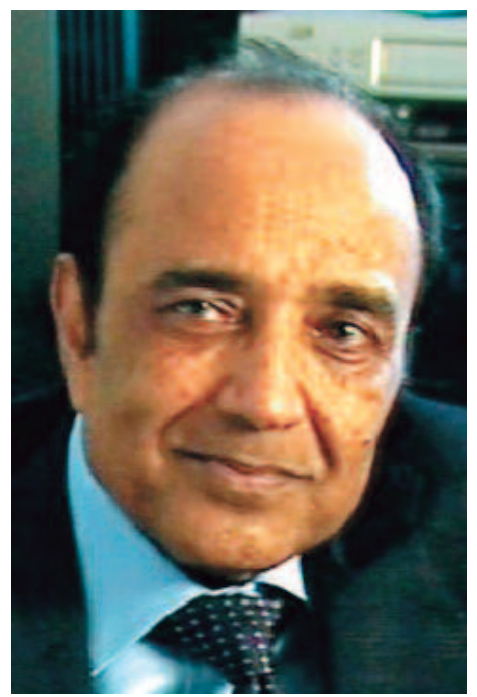

Mr Vasant Oswal MB MS FRCS (Ed) FRCS (Eng)

\section{International Laser Licensing System (ILLiS)}

As I am sure many, if not all of you are familiar, the International Laser Licencing System (ILLiS) developed from the initial International Medical Laser Specialist (IMeLaS) initiative which was first held together with Laser Tokyo 2009, at which I had the honour of being the Meeting President. Following the first IMeLaS course, it was pointed out that other medical professionals were equally involved with laser in surgery and medicine as doctors, dentists, veterinarians, laser scientists and so on, but were not covered under the previous guidelines for candidacy. The name of the initiative was therefore changed in 2010 to the current acronym, ILLiS, allowing other paramedical professional to be encompassed as candidates such as laser nurses, laser engineers, laser safety officers and so on. The ILLiS initiative is administered by the WFSLMS and the ISLSM, and ILLiS courses are usually held at congresses of societies who are under the WFSLMS umbrella. 
Candidates for an ILLiS qualification fall under six categories, as follows:

\begin{tabular}{clll}
\hline No & & \multicolumn{1}{c}{ Category } & Acronym \\
\hline 1: & International Medical Laser Specialist & IMeLaS & Position \\
\hline 2: & International Dental Laser Specialist & IDeLaS & Qualified dentists \\
\hline 3: & International Veterinary Laser Specialist & IVeLaS & Qualified veterinarians \\
\hline 4: & International Laser Nursing Specialist & ILNuS & Qualified laser nurses \\
\hline 5: & International Laser Engineering Specialist & ILES & Qualified Laser Engineer \\
\hline 6: & Physicist International Laser Specialist & P-ILaS & Qualified scientist \\
\hline
\end{tabular}

For full information, please check with Laser Therapy, 2014; 23: pp 294-296, or visit https://www.jstage.jst.go.jp/article/islsm/23/4/23_14-AM-09/_article

I urge all interested persons to watch for announcements of future ILLiS courses, and either use the application forms found on that meeting's website, or copy the ones from the Laser Therapy article referenced above. Please note that the certification is for the most part for 5 year periods, and needs to be renewed for the certificate to continue to be valid. The first set of ILLiS (then IMeLaS) certificates expired in December of 2014, and those ILLiS certificates issued at the 2010 APALMS meeting (held in Suwa City, Japan), will expire in October of this year. Please be sure to keep your certification valid.

\section{End Notes}

We are half-way through the United Nation's International Year of Light, and the ELA/ESLAS meeting just held in Athens, the IPTA meeting in July and the ISLSM in August are all recorded on the IYL website as meeting of interest. Long-term readers will know that I have always been a great believer in the strong connection and essential synergy of light and life, so this year means a great deal to me. Man cannot exist without light. Without light, plants will wither and die. There are a very few organisms that have evolved to live in environments where there is no, or very little light, but for the vast majority of living things, light is life, Lasers, and to a lesser extent, other light sources used in medicine and surgery, harness this quintessential power, and use it to heal wounds and control pain. I am extremely proud to have been part of the development of laser and light in surgery and medicine for over 40 years, and I treasure Laser Therapy as a focus and forum for continuing advances into this exciting field. Please, keep you papers coming! Have a happy summer, and for those in the Southern Hemisphere, may your winters not be too arduous.

Tokyo, June 2015 